Article

\title{
Aboriginal Agency and Marginalisation in Australian Society
}

\author{
Terry Moore \\ School of Humanities, University of Tasmania, Private Bag 41, Hobart, Tasmania, 7001, Australia; \\ E-Mail: terence.moore@utas.edu.au; Fax: +61-3-6226-7847
}

Submitted: 9 March 2014 | In Revised Form: 23 June 2014| Accepted: 23 June 2014 | Published: 17 September 2014

\begin{abstract}
It is often argued that while state rhetoric may be inclusionary, policies and practices may be exclusionary. This can imply that the power to include rests only with the state. In some ways, the implication is valid in respect of Aboriginal Australians. For instance, the Australian state has gained control of Aboriginal inclusion via a singular, bounded category and Aboriginal ideal type. However, the implication is also limited in their respect. Aborigines are abject but also agents in their relationship with the wider society. Their politics contributes to the construction of the very category and type that governs them, and presses individuals to resist state inclusionary efforts. Aboriginal political elites police the performance of an Aboriginality dominated by notions of difference and resistance. The combined processes of governance act to deny Aborigines the potential of being both Aboriginal and Australian, being different and belonging. They maintain Aborigines' marginality.
\end{abstract}

\section{Keywords}

Aboriginal Australians; difference; discourse; identity politics; performative; social inclusion

\section{Issue}

This article is part of the special issue "Policing Ethnicity: Between the Rhetoric of Inclusion and the Practices and Policies of Exclusion", edited by Professor Abby Peterson (University of Gothenburg, Sweden) and Professor Malin Åkerström (University of Lund, Sweden).

(C) 2014 by the author; licensee Cogitatio (Lisbon, Portugal). This article is licensed under a Creative Commons Attribution 4.0 International License (CC BY).

\section{Introduction}

It is widely agreed that Aboriginal and Torres Strait Islander people are the most disadvantaged population category in Australia. They are excluded in their limited capacity to participate in the decision making of the wider society and control their own and the mainstream social and cultural environment. They are disadvantaged in terms of educational achievement, health, employment, and quality and adequacy of housing, amongst other dimensions. Their marginality was established in the first 100 years of settlement, with the dislocation, segregation, neglect and structural marginalisation of the colonial period. It was confirmed in the 'indifferent' inclusion and assimilation of the early national period (McGregor, 2011).

Since the late 1960s though, Australia sought to include diverse cultural minorities in the national commu- nity while retaining their cultural particularity. This is the multicultural accommodation. In the Aboriginal case the accommodation has been complicated by postcolonial sensitivities, most importantly the attempt to overcome the historic legacy and facilitate the capacity for selfdetermination. Australian governments have put much rhetorical and material effort into this project, with good success. Aborigines and Torres Strait Islanders are empowered in their capacity to make local decisions and have greater agency than before in the affairs of the wider community, and are included as citizens.

The ongoing success of the approach is though, in doubt. An inclusionary ceiling may have been reached in the early part of the twenty-first century. It is argued here that the ceiling is the result of the inadequate conceptualisations of Aboriginality on which the policies of the multiculturalist inclusion are based. A conceptual framework has centred on a stereotypically fixed, dis- 
crete and bounded Aboriginal culture, thoroughly different from that of White Australia, and notions of a unitary self and imposed victimhood. When embedded in policy, this framework has made it in the interests of Aboriginal political elites to discursively heighten the differences and exaggerate the oppositions, and in the process generate a resistance to inclusion.

This political work has not been easy in the face of significant actual cultural, subjective and material changes that have meant that Aboriginal lives depart significantly from the way they are represented in the framework. It has required a great deal of energy in the production of discourse and the control of the performance of a normative Aboriginality. This has been necessary to obfuscate the reality and so maintain the political leverage to be had from apparent compliance with the conceptual framework.

\section{The Historical Context}

Through the nineteenth century, the attitudes of the wider population towards Aborigines were largely of indifference and condescension on the basis of their supposed childlike inability to participate in the modern world as equals. They were conceived as inferior, excluded from legal and administrative institutions and subject to special laws. They could not belong to wider society as equals and had limited agency in shaping their lives. They often could not find work, and were rejected from schools on complaint and provided with second-rate health care. Though these attitudes and discriminations were contested by humanitarians, the period did begin the discursive constitution of Australia's diverse indigenous people as a singular, bounded, radically different, inferior and maligned population, and their comprehensive marginalisation. This exclusion was also integral to the 'constitution of [Australian] social identity' (Morris, 2001, p. 247).

At the 1901 deliberations over the constitution of the federation, and in the document itself, 'Aboriginal people [continued to be] outside the community of the Australian nation' (McGregor, 2011, p. xx). Their exclusion was such that the many living on reserves were 'impoverished, [their] housing was rudimentary, education was basic or non-existent, health status was low, and employment was forced and unremunerated' (Sullivan, 2011, p. 3).

In the years between the First and Second World Wars, policy was driven by an ethnic sense of nationalism, and Aborigines continued to be marginalised as 'citizens without rights' (Chesterman \& Galligan, 1997). Governments addressed the issue of a growing number of 'half-castes' with ambivalence. A horror of miscegenation meant that it was 'highly stigmatised and much was done officially to...prevent it' (Merlan, 2009, p. 308). Governments sought to segregate 'full bloods' on reserves on the basis that they were incapable of sur- viving in the modern world and would die out. At the same time, they sought to 'absorb' the half-castes by 'breeding out' their colour in order that they might fit in. Though never fully implemented, the intent was to remove them to institutions, provide them with basic training and leave them to merge into the wider community. Many contemporaries thought of this as progressive in 'relation to the prevailing racism' of the times (Flood, 2006, p. 224). Aboriginal activists sought citizenship and accepted that it was possible if traditional culture (not identity) was abandoned.

During this period, a nostalgic regard for Aboriginal 'spirituality, sociality and environmental sensitivity' emerged, contrasted favourably with the 'materialism, alienation and anomie of the West' (McGregor, 2011, p. 17). Many began to imagine such Aboriginal attributes as a source of a more authentic Australian-ness. In 1939 the Commonwealth officially conceived citizenship as 'the final objective of Aboriginal policy' (McGregor, 2011, p. 34).

In the aftermath of the Second World War and into the late 1950s, the ethnic sense of nationalism gave way to a more civic sense of a culturally plural nation based on shared civic values and way of life. Attempts were made to include Aborigines, at the expense of their social and cultural particularity. Particularly the lighter-skinned could be included as citizens with equal rights and responsibilities to the extent that they inculcated White norms and values, and adopted White codes of conduct and manner of living. Lighter-skinned children were removed to orphanages and adopted into white homes. This was coercive inclusion, compromised by a lack of civil rights. Many Aboriginal peoples' freedoms to marry, move, gain work and vote were limited, and even returned Aboriginal soldiers were treated unequally. This larger narrative was complicated by the urge to incorporate Aboriginal art forms, motifs and aesthetics into Australian heritage, by the complexity of the factors involved, and by some individuals' recognition of the benefits of their removal (Flood, 2006, pp. 227-233).

\section{The Multiculturalist Inclusion}

From the 1960s, efforts were made in Australia to develop a more pluralist concept of nation and include $A b$ original people within it, as citizens-with-a-difference. The approach responded to global developments such as wartime ethnic cleansing, human rights revolution, decolonisation, migration, US civil rights agitation, and recognition of the ethnic particularity of the national public sphere (Kymlicka, 2010, p. 100). The attempt has been to include people whose ethnic, religious and/or national background is different from the dominant Anglo heritage, without making assimilation to the dominant cultural norms the price of equal respect (Fraser, 1996). The attempt has been to respect diverse 
cultures within an inclusive national identity and a common civic culture as sources of social cohesion. In Australia this has been:

a highly integrative policy encouraging interaction between different people and full participation in mainstream society...It has involved very little cultural relativism, and has been primarily liberal in character, focused on individual rights to free enjoyment and expression of culture, rather than group rights (Moran, 2011, p. 2162).

The multicultural inclusion has been framed by liberal democratic values. It is dominated by the intent to facilitate migrant participation and engagement as equals in the wider society, by building supportive social networks within which migrants might participate, and institutions with which they felt at home. Kymlicka sees it as a process of 'democratic citizenisation', of:

turning the earlier...hierarchical relations [between minority and state and between the different sectors of the minority population] into relations of liberal democratic citizenship, both in terms of the vertical relations [with] the state and the horizontal relations amongst the members of different groups (Kymlicka, 2010, p. 100).

The key for Kymlicka is that the differential claims of different groups that arise can be managed by their 'filter[ing] and fram[ing] through the language of human rights, civil liberties and democratic accountability' (Kymlicka, 2010, p. 100).

This general approach to the accommodation of difference has underpinned the approach towards Aboriginal Australians. Their inclusion has been complicated by postcolonial sensitivities over their historic dispossession and homogenising assimilation, and by their insistence on sovereignty, group rights and separate status (Hunter, 2008; Maddison, 2009). In their case as a result, the usual tensions of including diverse cultural groups and maintaining a cohesive national society are heightened. Aboriginal inclusion has constituted a 'wicked problem' for policy, in part because Aborigines are wary of the potential for inclusion to be a neo-colonialism (Hunter, 2008, p. 7). The aim has been more to build Aboriginal capacities for selfdetermination in respect of their own affairs, and personal resilience, than the more integrative general approach. It has included the intent to enhance participation in the wider community, but been sensitive to the problem of homogenisation, and more geared toward the empowerment of difference.

The approach is built on a conceptual framework largely consistent with that which has dominated governmental thought since the colonial era and been used to gain control of a population regarded as 'unru-
Iy' (Foucault, 1979). The framework has featured a bounded, monolithic originary culture. The culture is primitive in being highly integrated, with each element critical to the health of the whole and each individual thought to unitarily represent the culture. The framework assumes a single, pan-Aboriginal culture very different from a similarly monolithic White Australian culture. This conceptualisation reprises the radical difference that justified colonisation and the collective identity that developed with colonialism.

The framework differs from its antecedents in reversing the colonial inferiority. The framework adopts the romantic view of precolonial Aboriginal culture and critique of Western individuality and materialism of the interwar years. It reverses the older hierarchy to valorise what was denigrated. In the framework, Aboriginality is more authentic as it approximates the originary precolonial or classical. In it too, Aborigines are victims to colonisation.

This framework has been central to the success and stalling of efforts to include Indigenous Australians. Those efforts began with the repeal of discriminatory legislation that had restricted access to social security (for unemployment, maternity allowance, family allowance, sickness benefits, the old age pension). They extended civil and political rights to Aborigines, including the right to consume alcohol and be paid equal wages, and recognised group rights such as to land.

The recognition of specific rights and attempt to ameliorate the legacies of colonisation influenced the formation of an 'Indigenous Sector' made up of 'thousands of publicly funded organisations' that facilitate the capacity for self-determination (Rowse, 2002; Sullivan, 2011). These organisations include remote Community Councils and urban community organisations providing legal aid and health services; Land Councils; Native Title Representative Bodies; the now-disbanded national representative body Aboriginal and Torres Strait Islander Commission (ATSIC); peak policy-making bodies at state and national levels; and cooperatives providing housing and other services. The Indigenous Sector has allowed Indigenous people greater choice, control of policy and capacity to control their own affairs.

The inclusion has also put enormous effort into adapting mainstream institutional structures and practices in order that they better cater to Indigenous needs. Institutions have addressed institutional racism and ethnocentric assumptions to remove barriers to Aboriginal participation and outcome. They have provided among other things, cultural competence training to staff, trained and employed Indigenous staff, implemented positive discrimination measures (e.g. dedicated positions and special entry provisions), and developed 'two-way' approaches that incorporate culturally-specific knowledge and processes in normal practice. This effort has been undertaken in accord with the conceptual framework above. 
Governments have facilitated the retention, recovery and revitalisation of cultural heritage. They have provided for museums, art galleries and keeping places' to research, preserve and display indigenous material culture, funded national celebrations and festivals, and promoted special days. Efforts have been especially marked in terms of symbolic recognition, like those of Prime Ministers Whitlam (who poured sand into the hands of a Gurindji elder to celebrate their ownership of their land (1975), Keating (who acknowledged dispossession and violence in the Redfern speech of 1992) and Rudd (who apologised in parliament in 2008 for past government actions). The national currency features Aboriginal figures from the national story, the national carrier flies a plane painted in an Aboriginal design, the forecourt of the parliament building features a large Aboriginal mosaic, and it may be becoming standard for Commonwealth Parliaments to open with a 'Welcome to Country' ceremony that indicates respect for original ownership.

These measures have helped Aboriginal capacity to engage with the wider society. The capacity is reflected in their political and discursive power (evident in the changes above and noting the successes in the 2012 Northern Territory election; see Rolls, 2014). There has also been some success in a redistributive sense. More equitable access has been provided to the social goods of education, health, housing and employment, there is a growing urban middle-class (Lane \& Lane, 2008), more young people in universities (Pechenkina \& Anderson, 2014) and a reduction in the life expectancy gap (Thomson et al., 2011).

These measures have resulted in a revaluing of Indigenous culture and cultural products. Though some Aborigines report institutional and individual racism, they are increasingly included as a matter of course in everyday social interaction, either as remarkable Aboriginal individuals or as unremarkable Australian citizens. The Australia Day Council and the national newspaper have for instance, named several Aborigines their 'Australian of the Year'. Widespread acceptance is evident in the largely supportive nature of the mainstream national and capital city newspapers, and television, the thousands who marched in solidarity with Aborigines in the Walks for Reconciliation of 2000, and the public support of a number of prominent Australians, including the head of the largest bank and a mining billionaire.

Relatedly, evidence points to the vast majority of Aborigines feeling a belongingness to the nation, of being Australian, while also belonging to their Aboriginal families and communities. This is indicated by the 4000 Indigenous people who enlisted in the Second World War (Reissman, 2012, 2014) and the majority of Aboriginal marriages, especially in the cities and among the better-educated, that are mixed (Heard, Khoo, \& Birrell, 2009). Most Aborigines now live as natives of the same liberal-democratic and human rights culture as their settler Australian compatriots, neighbours and partners, and are reasonably comfortable interacting with state institutions. There is little doubt that most would agree with the core values and democratic rights, liberties and responsibilities in the Australian Value Statement (Commonwealth of Australia, 2009). As the Aboriginal sprinter Cathy Freeman did when she celebrated her win in a 1994 Commonwealth Games race by draping herself in both Australian and Aboriginal flags, they enjoy multiple affinities.

\section{An Inclusion Ceiling}

The previous section characterised later twentiethcentury efforts to include Aborigines as successful. Morris (2001, p. 245) suggests that Aborigines 'have come to see themselves as indigenous subjects in their own right and not simply the objects of assimilation to be acted for or acted upon'. Self-confidence is one measure of the success of the multiculturalist approach taken to Aboriginal inclusion. The indicators of social advancement, political voice, citizen participation, popular acceptance and belongingness are others.

At the same time, there is evidence of persisting inequality and social separation that suggest that that inclusion is limited. Significant gaps remain in Aboriginal educational participation and attainment, health status, extent of home ownership and housing quality and overcrowding, unemployment and representation in the justice system (Australian Institute of Health and Welfare, 2013; de Bortoli \& Thomson, 2009). The gaps are more extreme in remote communities than urban. In some dimensions, such as the rate of smoking or deaths in custody, early improvements are stalled. In others, such as sexual violence, youth suicide, imprisonment, substance abuse, and literacy and numeracy, the gaps may be worsening.

These remaining gaps appear to be indicators of a ceiling to social inclusion. They are often cited as evidence of continuing governmental racism, indifference or other failure. And informal discrimination does continue alongside formal anti-discriminatory measures in the delivery of service (Cunneen, 2006; Moore, 2009). Over the past decade or so there has been a retreat from multiculturalism around the world, based on the claim that it is divisive and separatist (Barry, 2001; Sowell, 2004). A retreat has occurred in respect of the Aboriginal inclusion in Australia (e.g. Johns, 2008), and the Howard government (1996-2007) took a more normalising and individualising approach (AustinBroos, 2012; Sullivan, 2011).

The ceiling to inclusion is explained here in terms of a compromised Aboriginal engagement with the nation that is an unintended consequence of the attempts to include them. Depending as it has on the limited understandings institutionalised in public policy, the multiculturalist inclusion has invited Aboriginal political in- 
terests to adopt the same emphases on cultural recognition and internal bonding social capital, and to neglect the socio-economic equality and outward-looking bridging capital that are equally necessary for inclusion as different-equals. In some cases, like claiming rights to land, policy has made it necessary to adopt those emphases. This explanation takes seriously the potential danger ethnic separatism may pose for wider social cohesion (Moran, 2011, pp. 2156-2166) especially, given its bias to cultural recognition, in the Aboriginal case. The other concern developed in the essay is that the multiculturalist inclusion is having negative outcomes for Aborigines themselves and may be contributing to their socio-cultural isolation and socioeconomic marginalisation.

There are some signs of a possibly increasing Aboriginal sense of separateness and disengagement from the wider society that suggest the conclusion above. There is for instance, a continuing disengagement from standard schooling, reluctance to adopt public health messages and recent propositions for separate structures predicated on the idea of a distinct Indigenous epistemology and research methodology. It is to the ambivalence of Aboriginal desire to 'be included' that this essay turns. The essay explains the limits to further social inclusion as the result of the dynamics that have flowed from the multiculturalist inclusion and its inadequacy to increasingly diverse Aboriginal realities.

\subsection{The Discursive Aboriginal Reality}

The successes of the measures taken by Australian governments in their approach to the inclusion of Aboriginal people have been won largely on the back of the limited understandings of Aboriginality noted above and their institutionalisation in national policies, programs and practices. The same concepts and policies are also though, responsible for at least some of the waning of those successes. The concepts were always inadequate to the reality of Aboriginality and so less then fully effective in their implementation. Even in primitive cultures for instance, individuals do not replicate every facet of their culture, and stereotypes necessarily miss individual needs. In contemporary times, the approach to Aboriginal policy is increasingly inadequate to the more complex realities that are emerging, in part out of the very successes of the inclusion. More importantly, the approach is actively constraining that success.

Some Aboriginal activists have used the terms and conditions of the discourse and taken the political opportunities it has presented. Among them are the heads of bigger clans and those who are better educated in remote communities, many of whom serve as chairs of their community councils and can become 'big men' (Langton, 2008). Though the boundaries are not clearcut, the focus in this essay is on the elites of the cities and towns of the southern and coastal regions of the country. These are the leaders of relevant Indigenous Sector organisations, Indigenous sections in mainstream agencies and peak bodies, and academics. They have gained control of the interface with government and its funding, and appointments to and promotions within the many 'identified' positions (Pholi, 2012a). As 'interlocutors of government' (Rowse, 2005, p. 91), they have strategically taken up the invitation presented by policy discourse and participated in the dialogical creation of a mythological Aboriginality.

Activated by the privileged access to resources granted the Aboriginal subject of policy, notably in its authentic 'traditional' and disadvantaged forms, the urban elites are driven to approximate that subject in their politics. In order to secure their groups' access, they have 'seize[d] upon the minor differences' that distinguish them from those others with whom they nevertheless share their lives, and 'expand[ed] the identity gap between them' (see Kolsto, 2007, p. 161). They magnify the differences in the competition for access. This impulse to a 'narcissistic' focus on minor differences is strongest among groups whose differences from the wider society appear to outsiders to be relatively minor, though to insiders they may be affectively highly significant, indeed defining characteristics, as Ignatieff (1997) noted of the Yugoslav war.

There is clearly potential in this dynamic for social division, as in comparable situations in various parts of the world (Blok, 1998; Ignatieff, 1997; McCall, 2011). It is notable though, that in this case, Aboriginal urban elites direct much of their political entrepreneurship at the elaboration of a categoric difference that is in large part imagined by the state as a key means of their government. The elites mythicise the imagined originary culture and seek to take on its credentials. They amplify the differences between Aboriginality and a similarly monolithic Whiteness, making non- and anti-Whiteness additional signs of authenticity. And they stigmatise Whiteness and take on the status of innocent victim to Whiteness, and hence disadvantage. In this and what follows in the section, no judgement is made as to the validity of claims or the rightness or wrongness of positions taken; the intent is to indicate the political discourse and the Aboriginality being constituted (for relevant research literature see Moore, 2009, pp. 23-39, and for a Tasmanian case study pp. 166-195).

Via a constant stream of written and spoken word, visual art and other symbolic language, and in an infinite range of contexts-local and national cultural ceremonies and events; art openings; protest actions; public debates; election rallies; television, radio and newspaper reports and interviews; academic literature; government and consultancy reports; in autobiographies and political texts-the political elites signal the cultural authenticity of their constituencies. They assert their continuing kinship networks, communal structures and spiritual affiliation with, and responsibility to, their Country. They al- 
lude to their ancient ancestors and respected Elders. They cloak their people in these credentials of authorised authenticity. Those in the southern states seek the credentials of those in the north and centre, adopting skin names and artistic styles (while those in more remote areas use their more traditional-looking members to win land claims). In peak bodies' national policy statements these credentials are established as applying to all. In international fora, Aboriginal representatives mimetically assert their oneness with landed and oppressed others in the third world (Harrison, 2003; Merlan, 2009; Niezen, 2005). In these ways, the elites build a discourse of bounded, solidary and monolithic cultural authenticity, one that is now continually refreshed on a new national Indigenous television station.

These urban elites exaggerate their small differences in part by Othering (Barth, 1969; Cohen, 1991) White Australia, establishing the properties of their Aboriginality/Blackness by what it is not: a similarly monolithic Whiteness. Adopting White self-criticism, they exploit the colonial history to represent Whiteness in negative terms, as characterised by selfish individualism, greedy competitiveness and bourgeois concern for success, health, stability, status and material comfort. This differentiation can be accompanied by explicit rejection of sameness with others, as Pat Dodson did when he rejected the suggestion that Aborigines are reasonably well-integrated in the wider society. His grounds were that the suggestion 'really denies the uniqueness of who the indigenous people are' (Alcorn, 2008). This constitutes neat Aboriginal difference and non-Whiteness.

\subsection{The Discrepancies with Lived Reality}

The dialectic of state and Aboriginal discursive effort has constituted a hyperreal (Eco, 1986) Aboriginality that has become real in its consequences (Berger \& Luckman, 1966; Thomas \& Thomas, 1928) and established strong claims on the state on the basis of indigeneity, difference and discrimination. It is routinely represented in government policies and programs and operationalised in the delivery of services (in schooling, health care, welfare, housing, justice, etc.) around the country. It is a factor of significant but variable power in Aboriginal self-perception, core to their affective and ontological security, and conditioner of their behaviour, around the country. It is also largely taken for granted by White Australians, and it contributes by ascription to Aboriginal identity. Aboriginal political leaders are deeply invested in it too, since state concessions rest on it. For all this, it is at odds with the realities of the Aboriginal everyday.

With globalisation and the inclusive reforms of the past forty years, cultural particularity is not as it seems and difference is less clear-cut than it was. Today's Aboriginal cultures are very different from those of earlier times and that of the pan-Aboriginal hyperreal, neither impermeably bounded nor internally homogeneous (Moore, 2009, pp. 34-36). The culture in each locale differs from that in every other, according to the nature of the precolonial culture, the particular colonial history and its impacts on the earlier culture, and its contemporary geographic location vis-à-vis the rest of the population. Those cultures are changing in remote and urban locales as they intersect with global flows, electronic media, and with national society as transport improves and mining and tourism grow. They are deeply intersected by and incorporate much of the political and popular cultures of the West, with one of their few commonalities (of varying intensity) being the hyperreal Aboriginality and sense of self it produces.

Today's Aborigines are also very different from those of earlier times. The small urban middle class exemplifies their embeddedness in myriad social networks outside their notional Aboriginal community. They do not live by hunting and gathering, nor are they dominated by obligation to kin, community and traditional law. They are connected and intersubjectively share much with the non-Aboriginal others of their workplaces, social class, neighbourhoods, generations, sexual cultures and the like (Langton, 1993, pp. 28-32; Moore, 2011, pp. 428-429). Just as their daily lives are interconnected, so they are subjectively multiple and grow far beyond the assumed primitive metonym of the hypereal subject. They are simultaneously Aborigines and Australians, and the differences from other Australians are subtle rather than absolute.

The mis-match between the discursively imagined Aboriginality and everyday lived Aboriginalities makes the former constantly vulnerable to exposure. In Goffmanian terms, the unruffled Aboriginality of the discursive front stage is liable to descreditation by the messy lived back stage. The disjunctures are becoming increasingly evident, and leading to questioning and gradual erosion of the liberal consensus (Sutton, 2009). Why for instance, students in my courses quietly ask, ought an Aboriginal family whose children go to expensive schools, have extensive free access to tutoring? How, they wonder, can an urban Aboriginal community claim to run sustainable forestry on the basis of deep knowledge of the land? Why is it, trainee teachers ask tentatively, that they must learn how to teach Aboriginal students in culturally sensitive ways but not African refugees whose physical, social, linguistic and cultural differences are more clear-cut and whose needs are more urgent? The minor actual differences are troubling to many.

\subsection{Disciplined Performance of Normative Aboriginality}

The ever-present threat of the discrepancies to undermine wider faith, and with it the access to government resources, influences Aboriginal leaders to constantly refurbish the discourse and to rouse among 
their constituencies a performative Aboriginality. Leaders press their constituencies to enact that Aboriginality: its originary authenticity, clear difference and imposed disadvantage. With occasional input they nudge what becomes a self-sustaining social dynamic that presses individuals to behaviourally enact that Aboriginality and so to obfuscate their actual immersion in multiple worlds and subjective growth beyond it.

In the southern state of Tasmania, the attributes of authenticity-body type, skin colour, native language, landedness, ancient social arrangements and the likeare virtually absent, though much effort has gone into symbolically recreating them. There is little other than minor differences to enact, and their comprehensive performance can cloak the actor in the mythic Aboriginality. Attendance at community events (funerals, festivals and other meetings), drinking at certain pubs and political activism can indicate one's loyalty. Speaking Aboriginal English can work similarly, as the otherwise urbane mainland Aboriginal actor Aaron Pedersen did when he used Aboriginal English as host of the 2012 NAIDOC Ball in Hobart. Asserting one's landedness too, as a recently-identifying student at my university did when he asked, on meeting a visiting Aboriginal presenter, 'What country you from bro?' (personal observation). Arguably for the similar purpose of establishing her credentials, an urban Aboriginal lecturer told her students that 'I go at least once a year to [my] Country, where I can feel my ancestors' (Walter \& TomlinsJahnke, 2013).

Such enactment can assert one's sameness with Aboriginal insiders and difference from settler Australian outsiders. In accord with the political discourse, individuals can do the same by avoiding behaviours labelled as White. Not using Standard Australian English can indicate that the speaker is not guilty of wanting to be White or better than others. Non-Whiteness can also be demonstrated by routinely prioritising community events and family needs over work obligations, thereby demonstrating that White concern for career is a second priority.

Behaviours consistent with the discourse can convince the settler population, given the mythic (Barthes, 2000) character of the Aboriginality being enacted. The behaviours are necessary, but still may not win acceptance as insiders, since as Louis (2005) noted of the African American context, the politics mobilises minor differences to also exclude others who lay claim to belong. In Tasmania in the 1990s, a small group known as the Lia Pootah emerged who had recently discovered Aboriginal heritage and sought acceptance within the wider Aboriginal community. They undertook orthodox performances of Aboriginality-including the claim to be able to smell snakes in the bush as proof of their closeness to country-and gained some acceptance as Aborigines among the settler population. They however, lacked a recorded history of colonial subjugation, and were actively marginalised by the dominant sector of the Aboriginal population as inauthentic 'pop-ups' and 'paper blacks' (Moore, 2009, pp. 209-213).

The dynamics here, including the potential of discrepant realities to endanger the politics, contestations over authenticity, policing of others' behaviour, and performative Aboriginality, are national, as some examples suggest. In a seminar at the University of Queensland, a female Aboriginal academic told participants who were not confident about their Aboriginality that it was innate (personal communication). Aboriginal author Leah Purcell admonished a Tasmanian Aboriginal woman in print for accepting the half-caste/fullblood classification schema (Purcell, 2002, p. 213). In a dispute in Victoria, a number of 'fair-skinned' Aboriginal people brought a Federal Court challenge to claims made by a journalist that they chose to identify as Aborigines for dubious material ends (Bodey, 2011; Federal Court of Australia, 2011). In another dispute, a remote Aboriginal woman and Member of the Northern Territory Parliament rejected an urban Aboriginal academic's claims to shared culture and understanding of remote peoples' lives (Rolls, 2014, pp. 139-141).

Other Aborigines confirm the national character of the dynamic. Because disadvantage is discursively equated with the Aboriginal sense of self, Aboriginality and belongingness can be actualised by the display of disadvantage. Aboriginal woman Kerryn Pholi (2012b) says that to do so, she might:

recount my family's experiences of deprivation, perhaps with anecdotes of unpleasant experiences from my childhood. I may describe my extended family's ongoing disadvantage, complete with examples of my various relatives' health, legal and financial woes. I may reveal my personal experience of racism...or conversely, if I am paler in complexion I can describe the emotional pain I feel when my Aboriginal identity is unrecognised...If all else fails I can talk about my personal grief over the suffering of "my people".

She argues that this is a feature of urban Aboriginality, as it is easier to mobilise this Aboriginality in the absence of classic cultural distinctiveness.

Deviant Aboriginality, appearing as compliance with mainstream values and norms, may take myriad forms. It may show in the adoption of public health messages like taking care with diet, alcohol and lifestyle, or full engagement with education or career. As Pholi (2012b) says, for an Aborigine:

to pursue opportunities to move away from disadvantage is to reject one's Aboriginal identity and one's own family and community ... the benefits of education, employment and a middle class lifestyle [are] anathema to those who treasure their disadvantaged "Aboriginal" identity. 
Those who deviate can be pressured to normalise their behaviour. They may be characterised as wanting to be better than others, labelled an 'Uncle Tom', 'coconut', 'blackfella for nothing' or 'up-town nigger', names that challenge their Aboriginality and/or membership of the community (Morton, 1998). 'Flash' people, who put themselves outside the 'Indigenous domestic moral economy' to accumulate property, run the risk of being humiliated by rejection when they find themselves in need (Barwick, in Peterson \& Taylor, 2003, p. 114). A person who declines a drink may be accused of 'acting like a white man' (Brady, in Peterson \& Taylor, 2003, p. 113). This labelling can make it costly to transgress the norms.

Some individuals refuse the attractions of the model Aboriginality and the pressures to conform to it, and leave on display their aberrant interculturality, mixed loyalties, subjective multiplicity and capacity to negotiate the associated complexities. They suffer the challenges to their identity and belongingness that those behaviours attract. Torres Strait Islander, Professor Martin Nakata says $(2006$, p. 266) that when he and other Indigenous academics:

stray into perceived intellectualisms or activity that does not at first sight appear to have a direct relation to community interests, we can be called into question by our communities as to the relevance of our work and whether we are leaving community interests behind and becoming too immersed in the ways and thinking of the 'White' world...[We are pushed to consider] 'are we members of the Indigenous community or the academic community? The choice is sometimes that stark.

This hints at the threat of exclusion from the Indigenous community. It is, he says, to 'seek to regulate not just our thinking and intellectual activity, but also our identity' (Nakata, 2006, p. 266). This is in line with Pearson's statement that 'political or identity straitjackets...are imposed on' Aboriginal children to bind them to his community (Pearson, 2000, p. 63). Nakata and others have the personal capabilities to blur the boundaries and soften the hard edges of the notionally exclusive alternatives, and find ways of negotiating being both Indigenous and academic, but many do not.

A number of individuals persist in their individualised Aboriginalities and publicly question the politics, and then the regulatory pressure can increase. Pholi (2012b) says that:

the silencing of Aboriginal dissenters is centred on the "legitimacy and "authenticity" of the Aboriginal speaker, rather than the quality of the speaker's reasoning or expression. Silencing arguments also point to the speakers unsavoury character, which is evident through the offensive nature of his or her ideas, as well as through his or her apparent pandering to a "racist" enemy force.

Following her own critique of the politics, she was told 'you should not be proud of your disloyalty to your people' (2012b). Aboriginal intellectuals Noel Pearson and Marcia Langton have both trenchantly critiqued the politics, and been the targets of a good deal of Aboriginal and non-Aboriginal condemnation (Langton, 2007; Rothwell, 2008, p. 16).

\subsection{White Australian Contribution}

Identity is a product of self-assertion and others' ascription (Jenkins, 1998), and the contemporary Aboriginal self is the product of the Aboriginal and non-Aboriginal actions outlined above. Indeed, many White Australians work with and for Aboriginal people as teachers, nurses, social and other community workers. In the main, they accept the hyperreal Aboriginality and apply it in their relationships with Aboriginal people (see Kowal, 2010; Lea, 2008), and so contribute to those peoples' sense of self. They appreciate the need for 'culturally appropriate' service, accept the resentment directed at White Australia as justified, and feel they should neither intervene in self-determining Aboriginal pursuits nor assume that wider social norms are relevant.

These workers may worry about damaging culture, so neglect literacy and numeracy (Nakata, 2002, pp. 15-16), or excuse truancy as legitimate agency (Petray, 2013). They may wish to support Aboriginal family structures, so privilege potentially dangerous Aboriginal fostering arrangements over nurturing White alternatives (Moore, 2009, p. 313, note 38), or perpetrate racism by accepting without criticism Aboriginal behaviour that would not otherwise be accepted (Langton, see Zwartz 2008). In doing so, they contribute to the constitution of the Aboriginal hyperreality, and its compound effects.

It can be expected that these choices are made out of genuine belief, perhaps moral vanity (Pearson, 2007, p. 30), but also in the knowledge of the consequences of taking a more critical approach. Critics of the status quo are subject to a politics of embarrassment (Moore, 2009, pp. 201-205) that manipulates the notion that all critique is 'ignorant, paternalistic or racist' (Pholi, 2012b). Pholi says that as an Aborigine she "had the power to ruin a career with an accusation of insensitivity', and as Rolls (2014, p. 145) says, her 'experiences are typical'. The complexity ensures that those with whom Pholi worked would have faced formidable obstacles in defending themselves, which goes some way to explaining why so few do so. In any case, when issues do arise, institutions are often 'out of [their] depth' (Rolls, 2014, note 68), and do 'nothing, or when [they do] seek appeasement rather than address' (Rolls, 2014, p. 145). Individuals are on their own, liable 
to the 'mau-mauing' that Peter Sutton expected when he argued that classical culture is part of the problem of Aboriginal health (Sutton, 2001, p. 151).

\subsection{The Inclusion Ceiling}

The elaborate discursive, performative and policing machinery (Foucault, 1972, p. 220) sketched above appears to be disturbing many Aborigines (Moore, 2009, pp. 32, 233-240) and compromising their engagement in national society (Moore, 2009, pp. 240-244, 296297). The machinery regulates non-Aboriginal people in ways suggested by the timidity of the questions asked about the discrepancies between the discursive and lived realities. For Aborigines, the machinery impacts in urban and remote locations. In the latter it contributes to the choice of 'classical' behaviours like violence in dispute resolution, or fatalism about life's circumstances that negatively affect health and longevity (Sutton, 2001). The machinery can also lead some to demonstrate their non-Whiteness and Aboriginality by resisting inclusionary efforts. They may choose for instance, to disengage from school, not worry overly about diet (Gibson \& Pearson, 1987), continue smoking when pregnant (Ivers, 2011) or be ambivalent about the kind of house cleaning or parenting needed for child health (McDonald et al., 2009, p. 346). In these and other behaviours, the pressures are leading individuals to withdraw from 'being included', and so securing their own multidimensional social exclusion.

At the root of this effect is the heightening by the machinery of the tensions that attend inclusion. Initially in the abstract and ultimately in the everyday, the machinery turns manageable tensions into irreconcilable oppositions. It makes inclusion apparently cooption, Aboriginality antithetical to Whiteness and that which is shared with other humans, cultural change equivalent to cultural loss, and subjective multiplicity incompatible with Aboriginality. It has recognition become primary and inclusion secondary. These outcomes suggest that while the multiculturalist inclusion in the Aboriginal case may have initially rendered differential Aboriginal claims manageable through the language of human rights and civil liberties, as Kymlicka (2010) thinks, it has ultimately not done so. Instead, that very language has incited some claims-making based on exaggerated and mythic difference, and rendered them less manageable than they might otherwise be.

The approach has not adapted to take account of the social changes occurring with globalisation, and to which it has contributed. In Australia now, an unknown part of the problem of Aboriginal social exclusion and material disadvantage is the Aboriginality invented and defended for the governing purposes of the state and Aboriginal political elites.

\section{Through the Inclusion Ceiling?}

To this point, analysis has centred on the progressive approach taken by the Australian state to include Indigenous people in the wider society. The approach has sought to respect their cultural heritage and provide for their equality. In implementation the goal of recognition has prevailed over that of equality, and so constituted a ceiling to social inclusion. The analysis has suggested that the ceiling is ultimately an unintended consequence of the inadequate conceptualisation of Aboriginality that grounds the approach. Though abetted by strategic and unselfconscious Aboriginal agency, the conceptualisation and policy discourse have activated the generation of an exaggerated and unreal cultural difference, and a brittle, defensive strength.

The analysis suggests that the conceptualisation of Aboriginality must be refined if the inclusion ceiling is to be breached. The current conception in terms of an originary cultural authenticity, singular categoric identity and victimhood, makes all other forms less legitimate and drives the urge to difference. More sophisticated conceptions of cultural variability and change, simultaneous sameness and difference, identity multiplicity and mobility, and agentic capability, are critical if the tensions are to be made more manageable. In this, the everyday realities are instructive.

Some prominent Aboriginal leaders, amongst them Noel Pearson, Marcia Langton and Warren Mundine, demonstrate their subjective complexity, agency in transcending the oppositions, and embrace of some cultural change. They integrate in multiple networks of bonding and bridging type. They live and work within their local communities and the imagined national Aboriginal community. They also actively participate in social networks beyond those communities as Australian citizens. They negotiate the social interactions within and between those networks to become complex, expansive Aboriginal Australian selves. They respect classical Aboriginal cultures and the modern global, and demonstrate that it is possible to be culturally different from, and at the same time part of, the wider society in some respects and contexts.

These individuals and many others confirm the relationality and interculturality of contemporary Aboriginality and undermine the exclusive choice of Aboriginality or Australianness. Structural acknowledgement of these realities is necessary to further inclusion, insofar as it allows for the complexity that is actually so. The challenge is to develop policy that can foster expansive Aboriginalities. These individuals promote a 'constellation of challenging policy ideas' aimed at a 'radical centre' (Pearson, 2007) that avoids the shortcomings of the progressive left and neoliberal right. The policies of Pearson's Cape York Reform Agenda include: 
a transition from 'passive welfare' to conditional welfare; re-engagement with the 'real economy' through local economic development and orbiting; a return to high quality/high expectation secondary boarding schools; direct confrontation of 'addiction epidemics' and neglectful parents; and training of a new indigenous leadership, which would take responsibility for the necessary changes (Burke, 2013, p. 307).

Critical analysis suggests that substantive culture in remote areas will limit the success of policies such as these. Martin (2001) found that the demand to resist relations of dependence runs up against cultural traditions that validate such relations, and that loyalties to immediate kin limit the capacity for autonomous individuality. Moreover, the fractured nature of the communities involved limits the moral and political legitimacy to lead social change. Burke found that orbiting between the Warlpiri home in central Australia and their diaspora (mostly Northern Territory and South Australian towns) did not build external social networks or the 'rooted cosmopolitan' mix of the traditional and modern envisaged by Pearson (Burke, 2013; also Pearson, 2009, pp. 292-295).

It appears then, that policies like those of the Cape York Reform Agenda may work only partially in remote areas. And they are also not sufficiently nuanced to account for the subtle differences in urban locations. They are useful however, in providing direction for policy development aimed at further inclusion. The idea of the 'radical centre' rejects the focus on colonisation, racism and trauma as sole cause of disadvantage, and highlights the necessity of structural adjustment and Aboriginal responsibility for inclusion. Also, while the notion of the 'bicultural' orbiting person may not capture the simultaneous sameness and difference of interculturality, it can contribute to the development of policies more appropriate to expansive Aboriginality. And the focus on localised policy development and governance will be helpful in accounting for the differences between remote and urban Aboriginal needs.

\section{Conclusion}

Australia has struggled for twenty years with the realisation that the progressive policy framework aimed at including Aborigines is beginning to fail. In this paper I have made a case for a policy response at Pearson's 'radical centre'. I have argued that the progressive approach has led to the continuing marginalisation of Indigenous people, paradoxically as a result of the culturally sensitive attempts to accommodate them and their differences. The very attempt has provoked an exaggeration of differences and with that, eventual limits to inclusion. I have argued that the way to further inclusion is to better approximate the subtle mix of sameness and difference that most realise in their everyday lives. I conclude with two questions: 'How is contemporary Aboriginality to be conceived?', and 'How can policy provide for the real complexity of that Aboriginality?'. Resolutions to the dilemmas in both are required for greater Aboriginal inclusion as equals in Australian society and for the social cohesion of that society.

\section{Acknowledgements}

I acknowledge the useful comments of anonymous reviewers and the guest editors.

\section{Conflict of Interests}

The author declares no conflict of interests.

\section{References}

Alcorn, G. (2008). Aboriginal rebuke for G-G. The Age, 1 September 2008, p. 1.

Austin-Broos, D. (2012). Keeping faith with selfdetermination: Economy and cultural difference. Indigenous Law Bulletin, 7(29), 19-23.

Australian Institute of Health and Welfare. (2013). Aboriginal and Torres Strait Islander Performance Framework 2012: Detailed Analyses. Cat. No. IHW94. Canberra: AlHW.

Barry, B. (2001). Culture and Equality: An Egalitarian Critique of Multiculturalism. Cambridge, UK: Polity.

Barth, F. (Ed.). (1969). Ethnic Group and Boundaries: The Social Organisation of Culture and Difference. Bergen: Universitatsforlaget.

Barthes, R. (2000). Mythologies. London, UK: Vintage.

Blok, A. (1998). The narcissism of minor differences. European Journal of Social Theory, 1(1), 33-56.

Bodey, M. (2011). Andrew Bolt loses racial vilification court case. The Australian. Retrieved from http://www.theaustralian.com.au/media/andrewbolt-x-racial-vilification-court-case/story-e6frg9961226148919092

Burke, P. (2013). Indigenous diaspora and the prospects for cosmopolitan "orbiting": The Warlpiri case. The Asia Pacific Journal of Anthropology, 14(4), 304-322.

Chesterman, J., \& Galligan, B. (1997). Citizens without Rights: Aborigines and Australian Citizenship. Cambridge, UK: Cambridge University Press.

Cohen, A. P. (1991). The Symbolic Construction of Community. London: Routledge.

Commonwealth of Australia. (2009). Life in Australia. Retrieved from https://www.immi.gov.au/living-inaustralia/values/book/english/lia_english_full.pdf

Cunneen, C. (2006). Racism, discrimination and the overrepresentation of Indigenous people in the criminal justice system: Some conceptual and explanatory issues. Current Issues in Criminal Justice, 17(3), 329-46. 
De Bortoli, L., \& Thomson, S. (2009). The Achievement of Australia's Indigenous Students in PISA 2000-2006. Camberwell: ACER Press.

Eco, U. (1986). Travels in Hyperreality. San Diego, USA: Harcourt.

Federal Court of Australia. (2011). Eatok v. Bolt [2011] FCA 1103. Retrieved from http://www.austlii.edu. au/au/cases/cth/federal_ct/2011/1103.html

Flood, J. (2006). The Original Australians: Story of the Aboriginal People. Sydney: Allen and Unwin.

Foucault, M. (1972). The Archaeology of Knowledge. New York, USA: Harper and Row.

Foucault, M. (1979). The History of Sexuality, Vol One: An Introduction. London, UK: Allen Lane.

Fraser, N. (1996). Social justice in the age of identity politics: redistribution, recognition and participation. The Tanner Lectures, Stanford University, 3. Retrieved from http://tannerlectures.utah.edu/documents/ato-z/f/Fraser98.pdf

Gibson, M., \& Pearson, N. (1987). Anthropology and tradition: A contemporary Aboriginal viewpoint. Paper for ANZASS Conference, Townsville, Australia. Retrieved from http://www.freewebs.com/indigenous_ sobriety/Extra\%20Resources/Noel\%20Pearson\%20M erv\%20Gibson\%20Alcohol\%20and\%20Hopevale\%20 Community\%201987.pdf

Harrison, S. (2003). Cultural resistance as denied resemblance: Reconsidering nationalism and ethnicity. Comparative Studies in Society and History, 45(2, Apr.), 343-361.

Heard, G., Khoo, S.-E., \& Birrell, B. (2009). Intermarriage in Australia: Patterns by birthplace, ancestry, religion and Indigenous status. Clayton, Australia: Centre for Population and Urban Research, Monash University.

Hunter, B. (2008). Indigenous social exclusion: Insights and challenges for the concept of social inclusion. Brotherhood of St Laurence Social Inclusion Down Under Symposium, Melbourne, Australia, 26 June 2008.

Ignatieff, M. (1997). The Warriors Honor: Ethnic War and the Modern Conscience. New York: Henry Holt and Co.

Ivers, R. (2011). Anti-tobacco programs for Aboriginal and Torres Strait Islander people 2011. Canberra: Australian Institute of Health and Welfare, and Melbourne: Australian Institute of Family Studies.

Jenkins, R. (1998). Social Identity. London, UK: Routledge.

Johns, G. (2008). The Northern Territory Intervention in Aboriginal Affairs: Wicked problem or wicked policy? Agenda, 15(2), 65-84.

Kolsto, P. (2007). The "narcissism of minor differences" theory: Can it explain ethnic conflict? Philosophy and Society, 2(33), 153-173.

Kowal, E. (2010). The stigma of white privilege. Cultural Studies, 25(3), 313-333.

Kymlicka, W. (2010). The rise and fall of multiculturalism? New debates on inclusion and accommodation in diverse societies. International Social Science Journal, 61(199), 97-112.

Lane, J., \& Lane, M. (2008). Hard grind: The making of an urban Indigenous population. Bennelong Society Conference, Sydney, Australia.

Langton, M. (1993). Well I heard it on the radio and I saw it on the television... Woolloomooloo, Australia: Australian Film Commission.

Langton, M. (2007). Stop the abuse of children. The Australian. Retrieved from http://blogs.theaustralian. news.com.au/yoursay/index.php/theaustralian/com ments/stop_the_abuse_of_children

Langton, M. (2008). The end of "big men" politics. Griffith Review, 22, 11-38.

Lea, T. (2008). Bureaucrats and Bleeding Hearts: Indigenous Health in Northern Australia. Sydney: UNSW Press.

Louis, B. (2005). The difference sameness makes: Racial recognition and the "narcissism of minor differences". Ethnicities, 5(3), 343-364.

Maddison, S. (2009). Black Politics: Inside the Complexity of Aboriginal Political Culture. Sydney, Australia: Allen and Unwin.

Martin, D. F. (2001). Is welfare dependency "welfare poison"? An assessment of Noel Pearson's proposals for Aboriginal welfare reform. Centre for Aboriginal Economic and Policy Research, Discussion Paper No. 213. Canberra: CAEPR.

McCall, C. (2011). Culture and the Irish border: Spaces for conflict transformation. Cooperation and Conflict, 46(2), 201-221.

McDonald, E., Bailie, R., Grace, J., \& Brewster, D. (2009). A case study of physical and social barriers to hygiene and child growth in remote Australian Aboriginal communities. BMC Public Health, 9, 346.

McGregor, R. (2011). Indifferent Inclusion: Aboriginal People and the Australian Nation. Canberra: Aboriginal Studies Press.

Merlan, F. (2009). Indigeneity: Global and local. Current Anthropology, 50(3), 303-333.

Moore, T. (2009). The exhaustion of progressive Aboriginal governance. Unpublished Ph.D. dissertation. School of Government and Riawunna, University of Tasmania. Retrieved from: http://eprints.utas.edu. au/9959

Moore, T. (2011). Misadventures with Aboriginalism. Social Identities, 17(3), 423-441.

Moran, A. (2011). Multiculturalism as nation-building in Australia: Inclusive national identity and the embrace of diversity. Ethnic and Racial Studies, 34(12), 21532172.

Morris, B. (2001). Policing racial fantasy in the Far West of New South Wales. Oceania, 71, 242-262.

Morton, J. (1988). Essentially black, essentially Australian, essentially opposed: Australian anthropology and its uses of Aboriginal identity. In J. Wassman (Ed.), Pacific Answers to Western Hegemony: Cultural Practices of 
Identity Construction (pp. 355-385). Oxford, UK: Berg.

Nakata, M. (2002). Some Thoughts on the Literacy Issues in Indigenous Contexts. Melbourne, Australia: National Languages and Literacy Institute of Australia.

Nakata, M. (2006). Australian Indigenous Studies: A question of discipline. The Australian Journal of Anthropology, 17(3), 265-275.

Niezen, R. (2005). Digital identity: The construction of virtual selfhood in the indigenous peoples' movement. Comparative Studies in Society and History, $47(3), 532-551$.

Pearson, N. (2000). Our Right to Take Responsibility. Cairns: Noel Pearson and Associates.

Pearson, N. (2007). White guilt, victimhood and the quest for a radical centre. Griffith Review, 16(Winter), 11-58.

Pearson, N. (2009). Up From the Mission: Selected Writings. Melbourne: Black Books Inc.

Pechenkina, E., \& Anderson, I. (2014). Background paper on Indigenous Australian higher education: Trends, initiatives and policy implications. Retrieved from http://sydney.edu.au/documents/about/higher_edu cation/2011/20110930\%20IndigenousHigherEduca tionReview-ReseachPaper.pdf

Peterson, N., \& Taylor, J. (2003). The modernising of the Indigenous moral economy: Kinship, accumulation and household composition. The Asia Pacific Journal of Anthropology, 4(1-2), 105-122.

Petray, T. (2013). Punishing truancy is not the answer in Indigenous communities. The Conversation. Retrieved from: http://theconversation.com/punishingtruancy-is-not-the-answer-in-indigenouscommunities-21497

Pholi, K. (2012a). Why I burned my "Proof of Aboriginality". The Drum, ABC TV. Retrieved from http://www. abc.net.au/unleashed/4281772.html

Pholi, K. (2012b). Silencing dissent inside the Aboriginal industry. Quadrant Online. Retrieved from http:// www.quadrant.org.au/magazine/issue/2012/12/sile ncing-dissent-inside-the-aboriginal-industry

Purcell, L. (2002). Black Chicks Talking. Sydney: Hodder.

Reissmann, N. (2012). Defending Whose Country? Indigenous Soldiers in the Pacific War. Lincoln: University of Nebraska Press.

Reissmann, N. (2014). Unknown diggers. The Australian Financial Review, p. 46.

Rolls, M. (2014). The Northern Territory Intervention: The symbolic value of 'authentic' indigeneity and impoverishment, and the interests of the (progressive) liberal left. Coolabah, 13, 136-155.

Rothwell, N. (2008). Indigenous insiders chart an end to victimhood. The Australian Literary Review, p. 16.

Rowse, T. (2002). Indigenous Futures: Choice and Development for Aboriginal Australia. Sydney, Australia: University of New South Wales Press.

Rowse, T. (2005). Review article: Are Aborigines rooted? Australian Aboriginal Studies, 1, 91-96.

Sowell, T. (2004). Affirmative Action around the World: An Empirical Study. New Haven and London: Yale University Press.

Sullivan, P. (2011). Belonging Together: Dealing With the Politics of Disenchantment in Australian Indigenous Policy. Canberra, Australia: Aboriginal Studies Press.

Sutton, P. (2001). The politics of suffering: Indigenous policy in Australia since the 1970s. Anthropological Forum, 11(2), 125-173.

Sutton, P. (2009). The Politics of Suffering: Indigenous Australians and the End of the Liberal Consensus. Melbourne: Melbourne University Press.

Thomas, W. I., \& Thomas, D. S. (1928). The Child in America: Behaviour Problems and Programs. New York: Knopf.

Thomson, N., MacRae, A., Brankovich, J., Burns, J., Catto, M., Gray, C., Levitan, L., Maling, C., Potter, C., Ride, K., Stumpers, S., \& Urquhart, B. (2012). Overview of Australian Indigenous health status, 2011. Retrieved from http://www.healthinfonet.ecu.edu.au/overview _2012.pdf

Walter, M., \& Tomlins-Jahnke, H. (2013). Indigenous Studies: Australia and Aotearoa New Zealand. Retrieved from https://www.classcentral.com/mooc/ 1472/open2study-indigenous-studies-australia-andaotearoa-new-zealand

Zwartz, B. (2008). Martin condemns NT intervention. The Age, 3 September 2008, p. 11.

\section{About the Author}

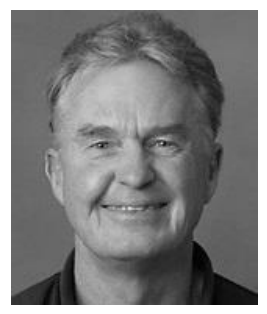

\section{Dr. Terry Moore}

Terry Moore is a political sociologist. His key research interests centre on the dilemmas thrown up by superdiversity, particularly those for Indigenous people in their negotiation of bothness, and for the state in its management of the tensions between proliferating difference and national social cohesion. He teaches Aboriginal Studies in social sciences and humanities, and cultural competence for trainees in various professions. 